23 Goldberg DJ, MacKinnon H, Smith R, Patel NB, Scrimgeour JB, Inglis J, et al. Prevalence of HIV among childbearing women and women having termination of pregnancy: multidisciplinary steering group study. $B M$ 1992;304:1082-5.

24 Sherr L. HIV and AIDS in mothers and babies. A guide to counselling. Oxford: Blackwell Scientific, 1991:57-68.

25 Boyd KM. HIV infection: the ethics of anonymised testing and of testing pregnant women. Institute of Medical Ethics: working party report. pred Ethics 1990;16:173-8.

26 Landesman S, Minkoff H, Holman S, McCalla S, Sijin O. Serosurvey of human immunodeficiency virus infection in parturients. $尹 A M A$ 1987;258: 2701-3.

27 Lindsay MK, Peterson HB, Feng TI, Slade BA, Willis S, Klein L. Routine antepartum human immunodeficiency virus infection screening in an innercity population. Obstet Gynecol 1989;74:289-94.

28 Wenstrom KD, Zuidema LJ. Determination of the seroprevalence of human immunodeficiency virus infection in gravidas by non-anonymous versu anonymous testing. Obstet Gynecol 1989;74:558-61.

29 Barbacci M, Repke JT, Chaisson RE. Routine prenatal screening for HIV infection. Lancet 1991;337:709-11.

30 Quinn TC, Glasser D, Cannon RO, Matuszak DL, Dunning RW, Kline R, et al. Human immunodeficiency virus infection among patients attending clinics for sexually transmitted diseases. N Engl f Med 1988;318:197-203.

31 Meadows J, Lenkinson S, Catalan J, Gazzard B. Voluntary HIV testing in the antenatal clinic: differing uptake rates for individual counselling midwives. AIDS Care 1990;2:229-33.

(Accepted 10 September 1993)

\section{Appendix}

SUMMARY OF THE RECOMMENDATIONS FROM THE SWEDISH NATIONAL BOARD OF HEALTH AND WELFARE CONCERNING HIV-SCREENING IN PREGNANCY ${ }^{9}$

1 Education and information about HIV in pregnancy should be given to all staff concerned with pregnant women and with newborns before antenatal HIV screening is started. The staff should be educated in medical, psychological, and hygienic issues to be able to inform the patient and feel confident in the work with HIV infected people.

2 The HIV test should be an integrated part of the antenatal care, and preferably performed at the same time as the other blood tests on registration at the antenatal care unit.
Pregnant women can also have the test performed at abortion clinics.

3 Adequate laboratory resources must be available for safe, rapid, and competent investigation of the blood samples. It is important that the time interval between blood sampling and the test result is kept as short as possible to reduce the period of uncertainty and to enable the woman to consider abortion if the test result is positive. Specific routines concerning test results should be used. A negative test result can be reported directly to the unit where the blood sample was collected. Women who have negative HIV test results or who decline the test should be given counselling according to their needs.

4 The woman must be informed about the tests and the reason for offering the test during pregnancy. The information should preferably be oral as well as written.

5 Local laboratories are supervised by the regional laboratories, at which the confirmatory tests should be performed.

6 When a test result is positive or indeterminate the laboratory should inform the responsible obstetrician directly, and then he or she is responsible for giving the information to the patient and for the following measures that need to be taken. There should be a special team with competence in obstetrics and gynaecology, paediatrics, psychology, social work, and infectious diseases within easy reach This team should take care of the counselling and support of the infected pregnant woman and her partner according to their needs. The obstetrician of the team is also responsible for the information to the staff concerned with the care of the patient and for the necessary hygienic precautions to be observed.

7 The result of the HIV test is written in the woman's pregnancy record. The HIV diagnosis must not be disclosed to anybody without the woman's consent. Children born to HIV-positive women need to be followed from birth, and the paediatrician should be notified by the team.

8 Contact tracing according to the law must be undertaken for the woman. Her partner and, where appropriate, her children should have an HIV test performed.

\title{
Relation between birth weight and blood pressure: longitudinal study of infants and children
}

\author{
Lenore J Launer, Albert Hofman, Diederick E Grobbee
}

\section{Department of}

Epidemiology and

Biostatistics, Erasmus

University Medical School, 3000 DR Rotterdam,

Netherlands

Lenore J Launer, research scientist

Albert Hofman, professor

Diederick E Grobbee,

professor

Correspondence to:

Dr Launer.

\section{Abstract}

Objective-To study the relation between birth weight and systolic blood pressure in infancy and early childhood.

Design-Longitudinal study of infants from birth to 4 years of age.

Setting-A middle class community in the Netherlands.

Participants-476 Dutch infants born in 1980 to healthy women after uncomplicated pregnancies.

Main outcome measures-Systolic blood pressure and body weight measured at birth and at 3 months and 4 years of age; the relation between systolic blood pressure and birth weight as estimated by multiple regression models that include current weight and previous blood pressure and control for gestational age, length at birth, and sex.

Results-Complete data were available on 392 infants. At 4 years of age the relation between blood pressure and birth weight appeared to be $U$ shaped; low and high birthweight infants had raised blood pressure. Current weight and previous blood pressure were also positively associated with blood pressure at that age. Low birthweight infants (birth weight $<3100 \mathrm{~g}$ ) had a greater gain in blood pressure and weight in early infancy. High birthweight infants (birth weight $\geqslant 3700 \mathrm{~g}$ ) had high blood pressure at birth, and weight and blood pressure tended to remain high thereafter.

Conclusions-Even among normal infants there seem to be subgroups defined by birth weight in which blood pressure is regulated differently. Future investigations are needed to examine the physiological basis of these differences. Studies of correlates of adult disease related to birth weight should investigate mechanisms related to increased risk separately in infants of low and high birth weight.

\section{Introduction}

An inverse relation between birth weight and cardiovascular disease in adulthood has been reported in retrospective cohort studies. ${ }^{1}$ The suggestion has been made that blood pressure mediates this relation. Indeed an inverse relation between birth weight and blood pressure has been reported in children, adolescents, and adults. ${ }^{2-4}$ Mechanisms for such a relation have been proposed ${ }^{5}$ but are by no means agreed on. ${ }^{6-8}$ Nevertheless, these findings raise the possibility that prenatal as well as postnatal factors are important in the aetiology of disorders in adulthood related to hypertension.

If prenatal factors and factors in early infancy contribute to disease in later life then examining prospectively their relation to blood pressure in the first years of life may help to elucidate this contribution. We examined the relation of birth weight to blood pressure in early infancy and childhood. We also studied the interrelation among birth weight, current 
body weight, and blood pressure to examine the postnatal effects of birth weight on blood pressure.

\section{Subjects and methods}

The 476 infants studied were born between 15 January and 15 December 1980 to healthy women with uncomplicated pregnancies who agreed in their seventh month of pregnancy to enter the infant into a randomised trial of high and low intake of sodium. 9 The infants were visited monthly from one week after birth to 25 weeks and then 439 were visited at 4 years of age. Complete data were available for 392 subjects up to 25 weeks of age and for 374 at 4 years of age. Most missing data were accounted for by missing or miscoded data on weight. There were no significant differences in birth outcome, weight, or blood pressure between those with and without missing data.

The attending midwife or physician provided the following data on birth outcome: gestational age by last menstrual period, weight measured to the nearest $100 \mathrm{~g}$, and length to the nearest $1 \mathrm{~cm}$. Subsequent measurements of weight and length were taken by the local health authorities responsible for infant health care. At 4 years of age measurements were made at home with floor scales and a microtoise meter. Four specially trained nurses, whose measuring techniques were standardised every two weeks, made monthly home visits starting when the infant was 1 week old and ending in week 25 to measure systolic blood pressure (mm Hg). They used a Parks 208A Doppler ultrasound device (cuff size $4 \mathrm{~cm}$ ) connected to a random zero sphygmomanometer, measuring pressure in the right arm when the infant was supine, awake, and not crying. This method measures blood pressure accurately in infants up to 6 months of age. ${ }^{10}$ Blood pressure at 4 years was measured at home by one nurse with a random zero sphygmomanometer (cuff size 10 $\mathrm{cm}$ ), which, in combination with the larger cuff, gives systematically lower readings than the ultrasound device. ${ }^{11}$

TABLE I-Mean (SD) ponderal indices and weights $\left(\mathrm{kg}^{*}\right)$ by birthweight group and age

\begin{tabular}{|c|c|c|c|c|c|}
\hline & \multicolumn{5}{|c|}{ Birthweight group } \\
\hline & $1(n=83)$ & $2(n=90)$ & $3(n=103)$ & $4(n=116)$ & Total $(n=392)$ \\
\hline Ponderal index (weight (length $\left.{ }^{3}\right)$ ) & $2 \cdot 5(0 \cdot 2)$ & $2 \cdot 5(0 \cdot 2)$ & $2 \cdot 6(0 \cdot 2)$ & $2 \cdot 7(0 \cdot 2)$ & $2 \cdot 6(0 \cdot 2)$ \\
\hline \multicolumn{6}{|l|}{ Weight (kg) at: } \\
\hline Birth & $2 \cdot 8(0 \cdot 2)$ & $3 \cdot 2(0 \cdot 1)$ & $3 \cdot 5(0 \cdot 1)$ & $4 \cdot 0(0 \cdot 3)$ & $3.4(0.5)$ \\
\hline 3 Months $†$ & $5 \cdot 1(0.5)$ & $5.5(0.6)$ & $5.6(0.5)$ & $5.9(0.6)$ & $5 \cdot 6(0 \cdot 6)$ \\
\hline 4 Yearst‡ & $16.5(1.9)$ & $17 \cdot 3(2 \cdot 2)$ & $17 \cdot 6(2 \cdot 2)$ & $18 \cdot 4(2 \cdot 2)$ & $17 \cdot 5(2 \cdot 2)$ \\
\hline \multicolumn{6}{|l|}{ Weight gain $(\mathrm{kg})$ between: } \\
\hline $0-3$ Monthsf & $2 \cdot 3(0.5)$ & $2 \cdot 3(0.6)$ & $2 \cdot 1(0 \cdot 5)$ & $1.9(0 \cdot 6)$ & $2 \cdot 1(0 \cdot 6)$ \\
\hline $0-4$ Years $\|$ & $13.7(1.9)$ & $14 \cdot 1(2 \cdot 2)$ & $14 \cdot 1(2 \cdot 2)$ & $14 \cdot 4(2 \cdot 2)$ & $14 \cdot 1(2 \cdot 2)$ \\
\hline
\end{tabular}

*Birth weight given in $\mathrm{kg}$ rather than $\mathrm{g}$ for purposes of comparison.

†By analysis of variance, trend in weight by birth weight is significant $(p<0.0001)$; mean weight of infants in high birthweight group (4) is significantly higher than that of infants in other groups $(p<0.0001$ for all groups). Analyses adjusted for infant sex.

$\ddagger$ Sample sizes per increasing birthweight group are $79,85,101,109$; total $=374$

BBy analysis of variance, trend in weight gain by birth weight is significant $(p<0.0001)$; weight gain of infants in low birthweight group (1) is significantly higher than that of infants in birthweight groups 3 and $4(p<0.04$ for both groups). Analyses adjusted for infant sex.

$\|$ By analysis of variance, trend in weight gain by birth weight is significant $(p=0.05)$; weight gain of infants in high birthweight group (1) is greater than infants in low birthweight group (1) $(p=0.05)$. Analyses adjusted for infant sex.

TABLE II-Relation (inear regression coefficient (SE)) between current systolic blood pressure ( $\mathrm{mm} \mathrm{Hg}$ ), past systolic blood pressure, and weight $(\mathrm{kg})$ by age

\begin{tabular}{|c|c|c|c|c|c|c|}
\hline \multirow[b]{2}{*}{ Age ${ }^{\star}$} & \multicolumn{6}{|c|}{ Independent variables } \\
\hline & Intercept & $\begin{array}{l}\text { Birth weight } \\
\text { (linear) }\end{array}$ & $\begin{array}{l}\text { Birth weight } \\
\text { (quadratic) }\end{array}$ & $\begin{array}{c}\text { Blood pressure } \\
\text { at } 1 \text { week }\end{array}$ & $\begin{array}{l}\text { Weight } \\
\text { (current) }\end{array}$ & $\begin{array}{c}\text { Blood pressure } \\
\text { at } 3 \text { months } \dagger\end{array}$ \\
\hline 1 Week & $\begin{array}{c}56.95(41.60) \\
(p=0.17)\end{array}$ & $\begin{array}{l}10.81(3.31) \\
(p=0.001)\end{array}$ & $\mathrm{p}<0.27 \ddagger$ & & & \\
\hline 3 Monthst & $\begin{array}{c}91.36(17.13) \\
(\mathrm{p}<0.001)\end{array}$ & $\begin{array}{l}-4.33(1.53) \\
(p=0.005)\end{array}$ & $\mathrm{p}<0.27 \ddagger$ & $\begin{array}{l}0.15(0.02) \\
(p<0.0001)\end{array}$ & $\begin{array}{l}2.28(0.95) \\
(p=0.02)\end{array}$ & \\
\hline 4 Years & $\begin{array}{c}79 \cdot 1 \quad(23.00) \\
(p=0.0006)\end{array}$ & $\begin{array}{c}-19.73(9.77) \\
(p=0.04)\end{array}$ & $\begin{array}{c}2.60(1.36) \\
(p=0.06)\end{array}$ & $\begin{array}{l}0.04(0.02) \\
(p=0.05)\end{array}$ & $\begin{array}{l}1.22(0.20) \\
(\mathrm{p}<0.0001)\end{array}$ & $\begin{array}{l}0.23(0.05) \\
(p<0.001)\end{array}$ \\
\hline
\end{tabular}

*Model also adjusted for infant sex, gestational age (weeks), and birth length $(\mathrm{cm})$.

tAverage of blood pressure from 13 weeks to 25 weeks of age.

$\ddagger$ Non-significant and not included in model.
The outcome measures were blood pressure at 1 week, 3 months, and 4 years of age. All children had two measurements of blood pressure at each visit, the mean of which was used in the analyses. The blood pressure at 3 months was an average of six measurements taken between 13 and 25 weeks of age. Since blood pressure remains fairly stable after the initial rise during early infancy ${ }^{12}$ the average was used to give a more stable estimate.

These outcome measures were studied in relation to birth weight $(\mathrm{g})$, current weight $(\mathrm{kg})$, and previous measurements of blood pressure $(\mathrm{mm} \mathrm{Hg}$ ) by using univariate and then multiple regression models. The multivariate models included all the above independent variables of interest as well as gestational age (weeks), birth length (cm), and sex. A non-linear relation between blood pressure and birth weight was tested by examining the fit of the model when a quadratic birthweight term was entered into the regression model after a linear term. The influence of points that could have had undue effect on the model was also examined. Because birth weight is included in the multivariate models, the coefficient for current weight can be interpreted as the effect of weight gained between birth and the time of the measurement.

Mean (SD) differences and trends in blood pressure and weight by birthweight group were estimated by analysis of variance. Birthweight group was defined by the quarters of the total birthweight distribution; because of missing values and rounding of the birthweight data to $100 \mathrm{~g}$ the birthweight groups are not equal in size. Results for the lowest and highest quarters are emphasised; the group in the lowest quarter is referred to as the low birthweight group (birth weight $<3100 \mathrm{~g}$ ) and the group in the highest as the high birthweight group (birth weight $\geqslant 3700 \mathrm{~g}$ ).

Two additional analyses were undertaken. A variable indicating which group in the trial of sodium intake the infant had been allocated to was entered into all final models, but no effect was found. To ensure that the systematic difference in blood pressure readings between infancy and 4 years of age due to instrumentation did not influence the results of the multivariate analyses pertaining to the 4 year olds, we converted all blood pressure values to age specific $\mathrm{Z}$ scores and reanalysed the data. The results were no different from those reported here.

The analysis was conducted with the SAS package. ${ }^{13}$ A two tailed probability test was used to assess whether a regression coefficient was different from zero, with $\mathrm{p}<0.05$ interpreted as significant.

\section{Results}

At birth the infants had a mean (SD) weight of 3400 (500) $\mathrm{g}$, length of 51 (2) $\mathrm{cm}$, and gestational age of 40 (1) weeks. Low birthweight infants had lower blood pressures at birth than high birthweight infants $(82 \cdot 0$ (18.9) $\mathrm{mm} \mathrm{Hg} v 92.6(20.1) \mathrm{mm} \mathrm{Hg})$ but had a relatively greater increase in blood pressure between birth and early infancy $(31.3(18.1) \mathrm{mm} \mathrm{Hg} v 21.2$ $(18 \cdot 6) \mathrm{mm} \mathrm{Hg}$ ).

Infants in the high birthweight group had the highest attained weight at all ages and gained more weight between birth and 4 years of age (table I). Although infants in the low birthweight group remained consistently lighter than infants in the high birthweight group, they gained proportionately more weight between birth and 4 years of age. They also gained considerably more weight between birth and 3 months of age than the infants in the high birthweight group.

Table II presents the multiple linear regression analyses of the relation between blood pressure and birth weight at all three ages. Birth weight was 
TABLE III-Adjusted means (SD)* of systolic blood pressure ( $\mathrm{mm} \mathrm{Hg}$ ) at 4 years of age by birthweight group and quarter of weight gain from birth to 4 years

\begin{tabular}{lccccc}
\hline $\begin{array}{c}\text { Quarter } \\
\text { of weight } \\
\text { gain }\end{array}$ & \multicolumn{5}{c}{ Birthweight group } \\
\cline { 2 - 5 }
\end{tabular}

*Adjusted for infant sex, gestational age (weeks), and birth length $(\mathrm{cm})$. Adjusted value calculated as follows: $\mathrm{Y}_{\text {adj }}$ " $\mathrm{y}-\left(\beta_{\mathrm{x} 1}^{\star}{ }^{\star}(\operatorname{sex})\right)-\left(\beta_{\mathrm{x}_{2}{ }^{\star}}\left(\mathrm{x}_{2}-\overline{\mathrm{x}}_{2}\right)\right)-\left(\beta_{\mathrm{x}_{3}{ }^{\star}}{ }^{\star}\left(\mathrm{x}_{3}-\overline{\mathrm{x}}_{3}\right)\right)$.

†By analysis of variance, trend in blood pressure by quarter of weight gain is significant $(p<0.002)$ within birthweight group.

$\$$ By analysis of variance, mean blood pressure is higher than all other means $(p<0.05)$ for all groups except high birth weight (4) and high weight gain group (4), where $\mathrm{p}<0.06$.

positively associated with blood pressure at 1 week of age. In contrast, birth weight was negatively associated with blood pressure at 3 months of age. At 4 years of age there was a distinct $U$ shaped relation between birth weight and blood pressure, indicating that both lower and higher birthweight infants had raised blood pressures (figure). The unadjusted coefficients describing this $\mathrm{U}$ shaped relation were similar (linear term 18.9 (SE 10.29), $\mathrm{p}=0.07$; and quadratic term 2.8 $(1 \cdot 46), \mathrm{p}=0.06)$.

Data on the relation between blood pressure, previous blood pressure, and current weight help describe the evolution of the $U$ shaped relation (table II). Blood pressure at 1 week was positively associated with blood pressure at 3 months and 4 years, and blood pressure at 3 months was positively associated with that at 4 years. Thus infants who had higher blood pressure at birth (that is, high birthweight infants) or those who had a relatively rapid increase in blood pressure during early infancy (that is, low birthweight infants) tended to have higher blood pressure at 4 years. Current weight was positively and significantly associated with blood pressure at 3 months and 4 years so that heavier infants (that is, high birthweight infants) and infants with high weight gain tended to have higher blood pressure at 4 years. Adjusted means (SD) shown in table III further elucidate the joint effects of birth weight and weight gain on blood pressure at 4 years. The blood pressure of infants in the group with low birth weight and high weight gain was significantly higher than that in any other group.

\section{Discussion}

The results from this longitudinal study suggest differences in the development of blood pressure among infants in the low and high birthweight groups.

Infants in the low birthweight group had lower than average blood pressure at birth but experienced a relatively large increase in blood pressure during early infancy. This increase may represent a catch up in blood pressure that is similar to the catch up in weight experienced by low birthweight infants ${ }^{14}$ and may reset blood pressure on to a higher track.

Continued weight gain resulted in significantly higher blood pressure in a subgroup of low birthweight infants compared with other infants. This finding could reflect the effect on blood pressure of the proportionately greater amount of weight gained in the low compared to higher birthweight infants. It may also reflect the effect of a third factor related to the increase both in weight and in blood pressure. Because of the magnitude of the difference in blood pressure in this subgroup relative to the others $(>5 \mathrm{~mm} \mathrm{Hg}$ ) further research is warranted to characterise better the mechanisms regulating the increase in weight and in blood pressure.

The pattern of development of blood pressure in high birthweight infants was different from that in the low birthweight group. The high birthweight infants had high blood pressure and weight at birth, which had a tendency to remain high. Blood pressure at 1 week was positively associated with blood pressure at 3 months, and blood pressure at both 1 week and 3 months was positively associated with blood pressure at 4 years. These infants also tended to experience a higher long term weight gain and weighed significantly more in late infancy and early childhood, a finding consistent with other studies of weight at birth and childhood. ${ }^{1617}$ Weight and weight gain were positively associated with blood pressure at 4 years.

The above findings suggest that even within this sample of infants who were healthy at birth there seem to be subgroups defined by differences in the pattern of development of blood pressure. Events in early infancy seem to be particularly indicative of these differences.
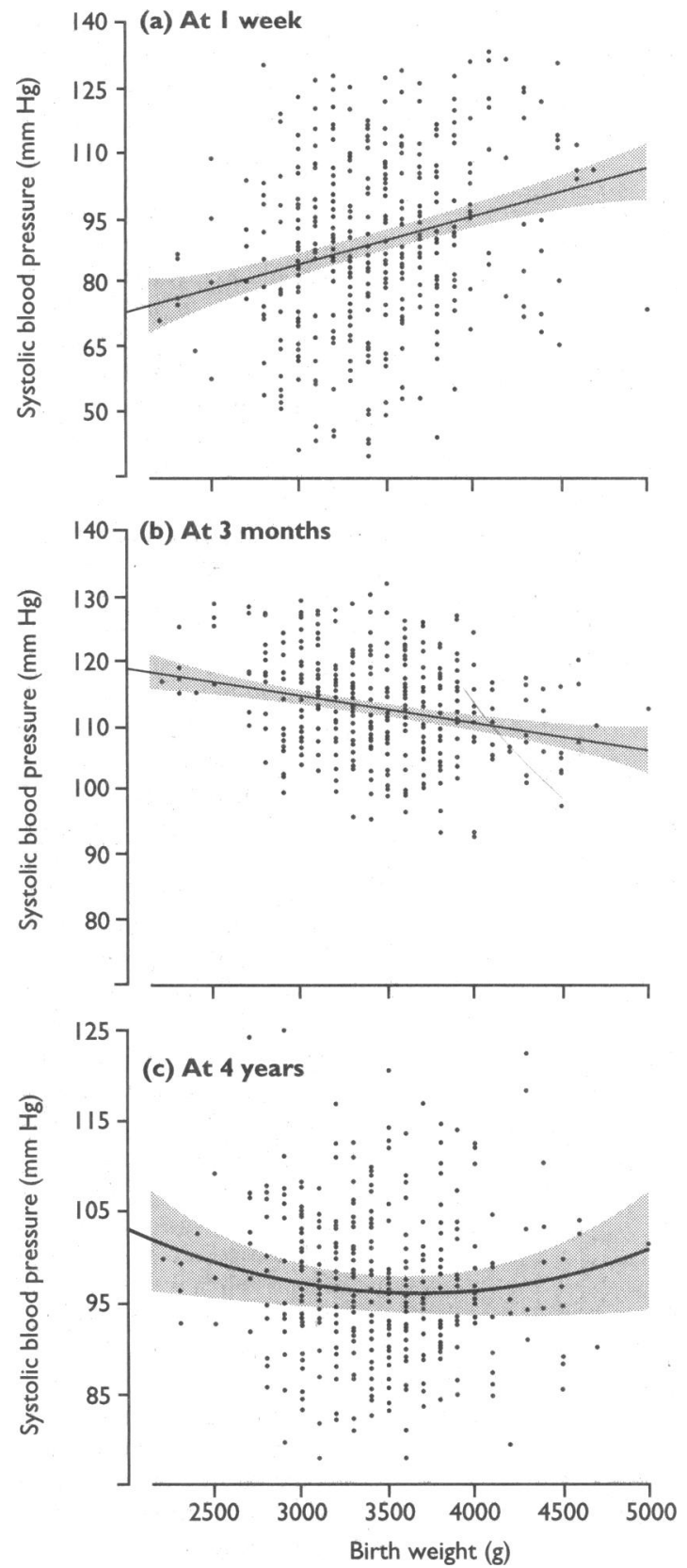

Relation between birth weight and systolic blood pressure ( $\mathrm{mm} \mathrm{Hg}$ ). (a) At 1 week $\left(\beta_{\text {birth }}=10.81\right.$ (SD 3.31)). Regression line adjusted for infant sex, gestational age (weeks), and birth length (cm). (b) At 3 months, where 3 months is an average of blood pressure from 13 weeks to 25 weeks $\left(\beta_{\text {birth weight }}=-4 \cdot 33(1 \cdot 53)\right)$. Regression line adjusted for infant sex, gestational age (weeks), birth length (cm), blood pressure at 1 week $(\mathrm{mm} \mathrm{Hg})$, and current weight ( $\mathrm{kg}$ ). (c) $\mathrm{At}$ 4 years $\left(\beta_{\text {birth weight }}=-19.73\right.$ (9.77); $\left(\beta_{\text {birth weight, quadratic }}=2.60\right.$ $(1 \cdot 36))$. Regression line adjusted for sex, gestational age (weeks), birth length $(\mathrm{cm})$, blood pressure at 1 week $(\mathrm{mm} \mathrm{Hg})$, blood pressure at 3 months $(\mathrm{mm} \mathrm{Hg})$, and current weight $(\mathrm{kg})$ 


\section{Clinical implications}

- An inverse relation between infant birth weight and cardiovascular disease in adulthood has been reported in retrospective cohort studies

- Studying the relation between birth weight and blood pressure prospectively from infancy to early childhood may help to elucidate the contribution of early life experiences to disease in later life

- This study shows that low and high birthweight infants have different patterns in development of blood pressure from infancy to 4 years of age

- At 4 years of age children who had had low or high birth weight had increased blood pressure

- These data suggest that the relation between birth weight and adult disease may be explained by different factors in low and high birthweight infants

Further research is needed to elucidate the factors related to these differences. The effect of birth weight on blood pressure in early infancy or on subsequent weight does not entirely explain the effect of birth weight at 4 years as birth weight remained importantly related to blood pressure after adjustment for these variables. Prenatal factors, such as hormonal environment, maternal diet, and genetic predisposition, or postnatal factors, such as infant diet and pattern of activity, should be studied as factors that set or maintain blood pressure at a fairly high level.

The relevance of these and similar findings to understanding the development of pathophysiology later in life remains debatable. In the absence of longitudinal studies from childhood to adulthood we can only postulate a link between early and later patterns of blood pressure from studies on tracking blood pressure, family history of hypertension, and the physiology of blood pressure in children. ${ }^{18-20}$ If childhood experiences are associated with events later on in life, as studies seem to indicate, then our findings lead us to suggest a $U$ shaped relation between birth weight and later onset of disease in healthy cohorts, with high birthweight infants and a subset of low birthweight infants being at increased risk. This $U$ shaped relation is in contrast to the model proposed by Barker and Martyn, who, on the basis of their findings, concluded that the risk for subsequent cardiovascular disease is inversely and linearly related to birth weight. ${ }^{21}$

Our cohort was not selected on the basis of birth weight, was healthy at birth, and grew up in a fairly homogeneous middle class environment. This sample contained few infants born before 37 weeks $(1 \cdot 2 \%)$ and few of birth weight less than or equal to $2500 \mathrm{~g}(1 \cdot 0 \%)$. Barket et al, however, reported preterm rates of 3.7\% ${ }^{4}$ and low birthweight rates of $3 \%{ }^{1}$ and $10 \%{ }^{5}$ in samples used to study the relation between birth weight and cardiovascular disease. The distribution of birth weight in a sample may influence the direction and importance of the relation between birth weight and adult outcomes if there are two different processes regulating blood pressure in low and high birthweight infants. Differences between low and high birthweight infants will also affect the outcome of studies on tracking blood pressure in infants and children. ${ }^{22} 23$

In summary, we found that birth weight had a $U$ shaped relation to blood pressure in 4 year old children. Further study of changes in blood pressure and weight in early infancy related to birth weight may help to elaborate this relation. Other factors should also be considered. Identification of these factors may eventually prove birth weight to be causally or noncausally related to disease outcomes in the future. A more refined conceptual model linking prenatal and postnatal events is needed to bring us closer to understanding the contribution of early childhood experiences to later adult diseases. Although this study was fairly small in size and of limited follow up, the results suggest that factors in early life that lead to high blood pressure need to be considered separately for low and high birthweight infants and that future research on this topic should take these differences related to birth weight into account.

We thank Mr D G Clayton for statistical advice, Drs J-P Habicht and S Harrap for comments on earlier versions of the manuscript, and Jolanda Bekker, Alice Hazebroek, Joke Jansen, and Ria Rijneveldshoek for their help in implementing this study. The study was kindly supported by grant 78.041 of the Netherlands Heart Foundation.

1 Barker DJP, Osmond C, Winter PD, Margetts B, Simmonds SJ. Weight in infancy and death from ischaemic heart disease. Lancet 1989;ii:577-80.

2 Whincup PH, Cook DG, Shaper AG. Early influences on blood pressure: a study of children aged 5-7 years. $B M$ f 1989;299:587-91.

3 Seidman DS, Laor A, Gale R, Stevenson DK, Mashiach S, Danon YL. Birth weight, current body weight, and blood pressure in late adolescence. $B M \mathcal{F}$ 1991;32:1235-7.

4 Barker DJP, Osmond C, Golding J, Kuh D, Wadsworth MEJ. Growth in utero, blood pressure in childhood and adult life, and mortality from

5 Barker DJP, Bull AR, Osmond C, Simmonds SJ. Fetal and placental size and risk of hypertension in adult life. $B M \mathcal{J}$ 1990;301:259-62.

6 Heath D, Williams DR. Fetal and placental size and risk of hypertension in adult life [letter]. BMf 1990;301:441.

7 Strachan DP, Hart JT. Fetal and placental size and risk of hypertension in adult life [letter]. $B M \mathcal{F}$ 1990;301:552.

8 Elford J, Whincup P, Shaper AG. Early life experience and adult cardiovascular disease: longitudinal and case-control studies. Int $f$ Epidemiol 1991;20:833-44.

9 Hofman A, Hazebroek A, Valkenburg HA. A randomized trial of sodium intake and blood pressure in newborn infants. FAMA 1983;250:370-3.

10 de Swiet M, Fayers P, Shinebourne EA. Systolic blood pressure in a population of infants in the first year of life: the Brompton study. Pediatrics 1980;65:1028-35.

11 de Swiet $M$, Fayers $P$, Shinebourne EA. Blood pressure in the first 10 years. BMF 1992;304:23-5.

12 Task Force on Blood Pressure Control in Children. Report of the second task force on blood pressure control in children-1987. Pediatrics 1987;79:1-25.

13 SAS Institute. SAS user's guide: statistics. Version 5. Cary, NC: SAS Institute, 1985.

14 Davies DP, Platts JM, Pritchard JM, Wilkinson PW. Nutritional status of light-for-date infants at birth and its influence on early postnatal growth. Arch Dis Child 1979;54:703-6.

15 Ounsted MK, Cockburn JM, Moar VA, Redman CWG. Factors associated with the blood pressures of children born to women who were hypertensive during pregnancy. Arch Dis Child 1985;60:631-5.

16 Garn SM. Relationship between birth weight and subsequent weight gain. $\mathrm{Am}$ f Clin Nutr 1985;42:57-60.

17 Binkin NJ, Yip R, Fleshood L, Trowbridge FL. Birth weight and childhood growth. Pediatrics 1988;82:828-34.

18 Zinner SH, Rosner B, Oh W, Kass EH. Significance of blood pressure in infancy: Familial aggregation and predictive effect on later blood pressure. Hypertension 1985;7:411-6.

19 Voors AW, Webbers LS, Berenson GS. Time course study of blood pressure in children over a three-year period. Bogalusa Heart Study. Hypertension 1980;2(1 suppl):I102-8.

20 Berenson GS, Lawrence $M$, Soto $L$. The heart and hypertension in childhood. Semin Nephrol 1989;9:236-46.

21 Barker DJP, Martyn CN. The maternal and fetal origins of cardiovascular disease. $\mathcal{F}$ Epidemiol Community Health 1992;46:8-11.

22 de Swiet $M$, Fayers $P$, Shinebourne EA. Blood pressure in the first 10 years of life: the Brompton study. BMF 1992;304:23-6.

23 Schachter J, Kuller LH, Perfetti C. Blood pressure during the first two years of life. Am $\mathcal{F}$ Epidemiol 1982;116:29-41.

(Accepted 22 September 1993)

\section{Correction}

Randomised controlled trial of oxytocin alone versus oxytocin and ergometrine in active management of third stage of labour

Two typesetting errors and an authors' error occurred in this paper by Susan J McDonald and colleagues (6 November, pp 1167-71). In the first line of table IV the number (percentage) allocated to oxytocin-ergometrine should have read 286 (16.5) (not $286(165 \cdot 5)$ ). Haemoglobin concentration was measured in $\mathrm{g} / \mathrm{l}$, so the second line of the left hand column of table $\mathrm{V}$ should have read "haemoglobin concentration $<91 \mathrm{~g} /$ ") (and not $<9.1 \mathrm{~g} / \mathrm{l}$ ). Similarly, on the 13th line the mean (SD) haemoglobin concentrations in $\mathrm{g} / \mathrm{l}$ should have read $114(14 \cdot 8)$ for oxytocinergometrine and $112(14 \cdot 1)$ for oxytocin (not $1 \cdot 4(1 \cdot 48)$ and $11 \cdot 2$ $(1 \cdot 41)$ respectively). 